\title{
Granger-causality analysis of integrated-model outputs, a tool to assess external drivers in fishery
}

\author{
Margarita María Rincón ${ }^{\mathrm{a}, *}$, Rachele Corti ${ }^{\mathrm{b}}$, Bjarki Thor Elvarsson ${ }^{\mathrm{c}}$, Fernando Ramos $^{\mathrm{d}}$, Javier Ruiz $^{\mathrm{a}}$ \\ ${ }^{a}$ Department of Coastal Ecology and Management, Instituto de Ciencias Marinas de Andalucía, Consejo Superior de \\ Investigaciones Científicas, Avda República Saharaui 2, 11519 Puerto Real, Cádiz, Spain \\ ${ }^{b}$ Ms.C. of Marine biology. School of Science. University of Bologna. Ravenna Campus, via S. Alberto 163, 48123 Ravenna, Italy \\ ${ }^{c}$ Marine and Freshwater Research Institute, Hafrannsóknastofnun, Skulagata 4, 121 Reykjavik, Iceland \\ ${ }^{d}$ Instituto Español de Oceanografía, Centro Oceanográfico de Cádiz, Puerto pesquero, Muelle de Levante s/n, Apdo. 2609,11006 \\ Cádiz, Spain
}

\begin{abstract}
Integrated models are able to combine several sources of data into a single analysis using joint likelihood functions, fostering the consistency of assumptions among analyses and the ability to diagnose goodness of fit and modelmisspecification. Owing to their capacity to consistently combine diverse information, integrated models could detect the variability induced by external drivers, such as various environmental drivers, on key components of the stock dynamics (e.g. recruitment) in cases where these external drivers are relevant but not yet identified or incorporated into the modelling exercise. This diagnosing power could then be used to explore causality between fishery dynamics, as estimated by the integrated model, and external drivers. To achieve this aim, a correlation analysis is neither necessary nor sufficient to prove causation. An alternative statistical concept, Granger-causality, provides a framework that uses predictability, rather than correlation, to give more evidence of causation between time-series variables.

A two-step procedure to investigate external forcings in stock dynamics is proposed. First, an integrated model is implemented to detect anomalies that cannot be explained by the internal dynamics of the stock. Then, in a second step, Granger-causality is used to detect the external origin of these anomalies. This two-step procedure is explored using the European anchovy in the Gulf of Cádiz as an example population where the external (environmental) drivers are well documented. The fishery dynamics is first estimated through an agelength model (Gadget). Then Granger-causality is used to assess the predictive power of different environmental drivers on recruitment. The results indicate that this is a powerful procedure, although also with important limitations, to determine predictability and that it can be implemented in a wide variety of stocks and external drivers. Moreover, once Granger-causality has been identified, it is shown that it can be used to forecast by making few modifications of the integrated model used for diagnosis.
\end{abstract}

\footnotetext{
* Corresponding author

Email addresses: margarita.rincon@icman.csic.es (Margarita María Rincón), rachele.corti@studio.unibo.it (Rachele Corti), bjarki.elvarsson@hafogvatn.is (Bjarki Thor Elvarsson), fernando.ramos@ieo.es (Fernando Ramos), javier.ruiz@icman.csic.es (Javier Ruiz)
} 
Keywords: Gadget model, environmental drivers, Granger-causality, European anchovy, ecosystem based fisheries management

\section{Introduction}

Population dynamics models aimed at supporting fishery management are increasingly incorporating data of different origin and nature to enhance their diagnosing capacities (Demyanov et al., 2006). Thus, assessing stock dynamics frequently relies on inferences from commercial catches but can also benefit from auxiliary information, such as survey indexes, fishing effort and length-age relationships, that is assimilated into models (Fournier and Archibald, 1982 , Deriso et al. 1985, Methot, 1989). Combining this diverse information is beneficial for quantitative assessments but it is also challenging, in particular when all this information is implemented together in the same model. The integrated analysis is able to combine several sources of data into a single analysis using joint likelihood functions, fostering consistency of assumptions among analyses and the ability to diagnose goodness of fit and model-misspecification (Maunder and Punt, 2013). Owing to their capacity to consistently combine diverse information, integrated models could detect the variability induced by external drivers, both environmental and from another source, on key components of the stock dynamics such as recruitment even in cases where these external drivers, despite being relevant, are not yet identified or incorporated into the simulation exercise. This diagnosing capacity could then be used to explore the forecasting power of external drivers on diagnosed fishery dynamics, as estimated by the integrated model.

To achieve this aim, a correlation analysis between the model output and the external driver is not enough to assess predictability. As in other fields of sciences, causality and correlation are too tightly associated in fisheries but correlation is neither necessary nor sufficient to prove causation (Yule, 1926). An alternative statistical concept, Granger-causality (Granger, 1969 , Sims, 1972), provides a framework that uses predictability, rather than correlation, to provide more evidence of causation between time-series variables. Granger-causality is considered (Sugihara et al. 2012) as the main advance on the causation problem since Berkeley's treatise on the principles of human knowledge (Berkeley and Krauth, 1874). Granger-causality states that an stationary time-series variable $X$ is said to "Granger-cause" (Granger, 1969) the stationary time-series variable $Y$, if past values of $X$ help to predict the current value of $Y$ better than just the past values of $Y$ do (Stern and Kaufmann, 2014). This concept has been extensively used in the field of economics (Masih and Masih, 1996; Mookerjee and Yu, 1997, Tedds and Giles, 2002, Foresti, 2006). In fishery science it has been recognized as useful to address the recruitment autocorrelation problem $(\overline{\mathrm{Ye}}, 2000)$, where autocorrelation could potentially increase or decrease our capacity to diagnose a stock-recruitment relationship (Gilbert, 1997, A. Myers and Mertz, 1998, Walters, 1985. Caputi, 1988). 
In this paper, we propose a two-step procedure to diagnose external forcings in stock dynamics. First, an integrated model is implemented to detect anomalies that cannot be explained by the internal dynamics of the stock. Then, in a second step, Granger-causality is implemented to detect the external origin of these anomalies. This two-step procedure is explored for the European anchovy in the Gulf of Cádiz where the external environmental drivers are well documented. First, the fishery dynamics are analysed with Gadget (Globally applicable Disaggregated General Ecosystem Toolbox), an age-length-structured modelling environment able to assimilate ¡ata on surveys and landings for parameter optimization through weighted likelihood components Begley and Howell, 2004). Then Granger-causality is used to assess the predictive power of different environmental drivers on recruitment. The results indicate that this is a powerful procedure, although also with important limitations, to assess predictability that can be implemented in a wide variety of stocks and external drivers. Moreover, once Granger-causality has been identified, it is shown that it can be used to forecast by making a few modifications of the integrated model used for diagnosis.

\section{Material and Methods}

As explained above, the stock of European anchovy in the Gulf of Cádiz was chosen to explore the procedure because environmental forcing of recruitment is well characterized. The modelling framework Gadget is used here owing to its ability to combine large pools of disparate data from diverse sources. Causality between estimated recruitment and environmental forcing was then assessed by using Granger-causality techniques.

\subsection{European anchovy in the Gulf of Cádiz}

The environmental vulnerability of the stock of European anchovy Engraulis encrasicolus at the Gulf of Cádiz is well documented. The stock is exploited under a BotTop pattern (Ruiz et al. 2007) where fishing mortality prevents adults from reaching older age groups and stock survival between years relies on early stages (Ruiz et al. 2006). Eggs and larvae occupy the sea shelf and are vulnerable to easterly winds. In contrast, juveniles occupy nursery zones close to or within the estuary of Guadalquivir River and are, consequently, sensitive to freshwater inputs into that habitat (Ruiz et al., 2009, González-Ortegón et al., 2010, González-Ortegón and Drake, 2012). It is then a neat case where known external drivers are forcing the dynamics of the stock and where the capacity of the procedure to detect Granger-causality can be tested.

Data of these external drivers were obtained from public databases. Daily wind between 1988 and 2009 was extracted from a meteorological database http://datosclima.es that stores information provided by the Spanish meteorological agency and then transformed into annual quarters by counting the number of days with easterly winds above $30 \mathrm{Km} / \mathrm{h}$ (Relvas and Barton, 2002, Ruiz et al., 2006, 2009, Peliz et al., 2013). Discharges 
from the Alcalá del Río dam (the main input of freshwater to the estuary) between 1988 and 2016 were obtained from the Confederación Hidrográfica del Guadalquivir (www.chguadalquivir.es).

The information incorporated into the integrated model was obtained from ICES reports as well as from different records on this stocks compiled by the Instituto Español de Oceanografía for the last decades. These include:

- Quarterly catches in numbers (1988-2015).

- Length distribution of landings (1998-2015).

- Age distribution of landings (1998-2015).

- Mean lenght at age in landings (1988-2015).

- Biomass indexes from ECOCADIZ scientific acoustic survey (second quarter 2004, 2006; third quarter 2007, 2009, 2010, 2013 and 2014).

- Age and length distribution of scientific acoustic survey ECOCADIZ (second quarter 2004, 2006; third quarter 2007, 2009, 2010, 2013 and 2014).

- Biomass indexes from PELAGO scientific acoustic survey (first quarter 1999, 2001-2003, second quarter 2005-2010, 2014).

- Age and length distribution of scientific acoustic survey PELAGO (first quarter 1999, 2001-2003, second quarter 2005-2010, 2014).

- Biomass indexes from SAR scientific acoustic survey (last quarter 1998, 2000,2001, 2007 and 2012 ).

\subsection{Integrated model}

To integrate different sources of information, the modelling framework Gadget was used to produce a synthesis of the stock dynamics. A typical Gadget model is an age-length-structured model that runs forward simulations while minimizing an objective function (negative log-likelihood) that measures the difference between the model and data. Discrepancies between model and data are presented as a likelihood score for each time period and model component. Gadget structure and options are described in detail by Begley and Howell (2004) with example implementations documented in Taylor et al. (2007); Bartolino et al. (2011); Elvarsson et al. (2018).

Gadget consists of three parts, simulation of the biological dynamics of the population (simulation model), fitting the model to observed data using a weighted log-likelihood function (observation model) and the optimization of the parameters using different minimization algorithms. 
In the first part, biological processes are simulated for a given set of model parameters in the following order: Predation by the fleets, natural mortality, growth, recruitment and ageing. This is repeated for all timesteps until the end of the simulation period. At the end of the simulation, the output of the objective (likelihood) function score is produced by comparing the model output to observed measurements. Then based on the objective function model parameters are adjusted, and the model re-run, until an optimum is found, which corresponds to the model with the lowest objective function (likelihood) score.

The model was set up as with quarterly timesteps from 1998 to 2015. Fisheries interactions were implemented by setting the purse-seine fleet as a predator and consequently catches (in numbers) data were included in the predation component of the first part. The remaining datasets listed above were used as observed measurements and combined in the objective function as a weighted sum of squares.

The weights of the likelihood components were assigned following the heuristic approach presented in Taylor et al. (2007) and in the appendix of Elvarsson et al. (2014) based on the iterative reweighting scheme of Stefánsson (1998) and Stefansson (2003). This weighting process is implemented in the gadget.iterative function in the $\mathrm{R}$ package (Elvarsson and Lentin, 2016). Data processing and input file formatting used the tools from the $m f d b \mathrm{R}$ package (Lentin, 2014) Further details on model parameterization, model validation and weighting of likelihood components are described in the Appendix.

\subsection{Granger-Causality analysis}

The typical Granger-causality test can be problematic because of non-stationarity of time series involved (He and Maekawa, 2001). Consequently, Toda and Yamamoto (1995) approach was followed here to apply the test when one or both of the time series are non-stationary (Zombe et al., 2017). The method to prove that $X$ Granger-cause $Y$ fits the following vector autoregressive model $(\operatorname{VAR}(\mathrm{L}+\mathrm{m}))$ :

$$
\begin{aligned}
Y_{t} & =a+\alpha_{1} Y_{t-1}+\alpha_{2} Y_{t-2}+\cdots+\alpha_{L} Y_{t-L}+\beta_{1} X_{t-1}+\beta_{2} X_{t-2}+\cdots+\beta_{L+m} X_{t-(L+m)}+\epsilon_{t} \\
X_{t} & =b+\delta_{1} X_{t-1}+\delta_{2} X_{t-2}+\cdots+\delta_{L} X_{t-L}+\theta_{1} Y_{t-1}+\theta_{2} Y_{t-2}+\cdots+\theta_{L+m} Y_{t-(L+m)}+\epsilon_{t}
\end{aligned}
$$

Where $L$ is the appropriate maximum lag length for the variables in the VAR, chosen using an usual information criteria, such as Akaike information criteria (AIC) (Akaike, 1974, 1998), $m$ is the maximum value chosen from the order of integration of time series $X_{t}$ and $Y_{t}$, and $\epsilon_{t}$ accounts for the error. Then, it is necessary to tests two hypothesis, $H_{0}^{1}: \beta_{i}=0, i=1, \ldots, L$ and $H_{0}^{2}: \theta_{i}=0, i=1, \ldots, L$ using a standard Wald test (aod $\mathrm{R}$ package, Lesnoff et al. 2012).

If there is enough evidence to reject $H_{0}^{1}$, i.e. to say that $\beta_{i}, i=1, \ldots, L$ coefficients are different from zero, 
and at the same time that there is not enough evidence to reject $H_{0}^{2}$, i.e. is highly probable that $\theta_{i}, i=1, \ldots, L$ coefficients are zero, we can say that X Granger-cause Y.

It is necessary to check also that the $\operatorname{VAR}(\mathrm{L})$ model is well-defined: stable and with non-serially correlated errors. Stable to guarantee that the variance is finite and that the matrix system has a solution, and non correlating, to avoid bias on the estimated coefficients (Lütkepohl, 2013). Stability was tested by calculating the eigenvalues of the matrix associated to the equivalent first-order vector autoregressive form and checking that they were less than one. Serial correlation for errors was tested with the multivariate Portmanteau and Breusch-Godfrey test (Lütkepohl, 2013, Breusch, 1978: Godfrey, 1978). Both tests are implemented in the V ARS $\mathrm{R}$ package $(\mathrm{Pfaff}, 2008)$ which were used here.

\subsection{Forecast}

If the environmental variable, $E$, Granger-cause the recruitment, $R$, the first equation of the well defined $\operatorname{VAR}(\mathrm{L})$ model is selected (equation (1) with $m=0$ ), restricted to significant coefficients and tested for nonserial correlation (Portmanteau test). Then, the population model is used to project stochastically based on a restricted version of this equation to provide a prediction of catches 3 years into the future (2016-2018). In each projection the recruitment was sampled from a normal distribution with mean derived from the restricted equation and standard deviation equal to the standard deviation of the fitted model residuals $\epsilon_{t}$. The values of the environmental variable in this equation are fixed to illustrate two different environmental scenarios: A base scenario assuming that environmental conditions remain constant and, an adverse scenario based on calculations to have a recruitment worse than the previous year. Resulting values are used as initial values for recruitment parameters in a Gadget simulation assuming a constant effort. The implementation details are listed in the Appendix.

\subsection{Reproducibility}

The manuscript was generated using a combination of $\mathrm{LAT}_{\mathrm{E}} \mathrm{X}$ and $\mathrm{R}$ codes with the $\mathrm{R}$ package knitr (Xie, 2014). "The knitr package was designed to be a transparent engine for dynamic report generation with R", where transparency means that the user has full access to every piece of the input and output (see https://yihui. name/knitr/). The file to assure reproducibility is included as Supplementary Material and the instructions and requirements to reproduce this document entirely are in the Appendix.

\section{Results}

Figure 1. illustrates the sum of squares of the differences between available and estimated data (likelihood scores). Together with Figures A.2 and A.3 (in the Appendix) show that the there is a reasonable match between 
modelled and observed age and length frequency distributions. This suggests that the model adequately explains the population dynamics as observed in the data. However, there is a notable poor fit in 1996 for age and length distribution of landings (Figures $1 \mathrm{~A}$ and $1 \mathrm{~B}$ ), just before the implementation of the minimum landing size regulation. The estimated parameter values are shown in Table $\mathrm{A}$ in the Appendix.
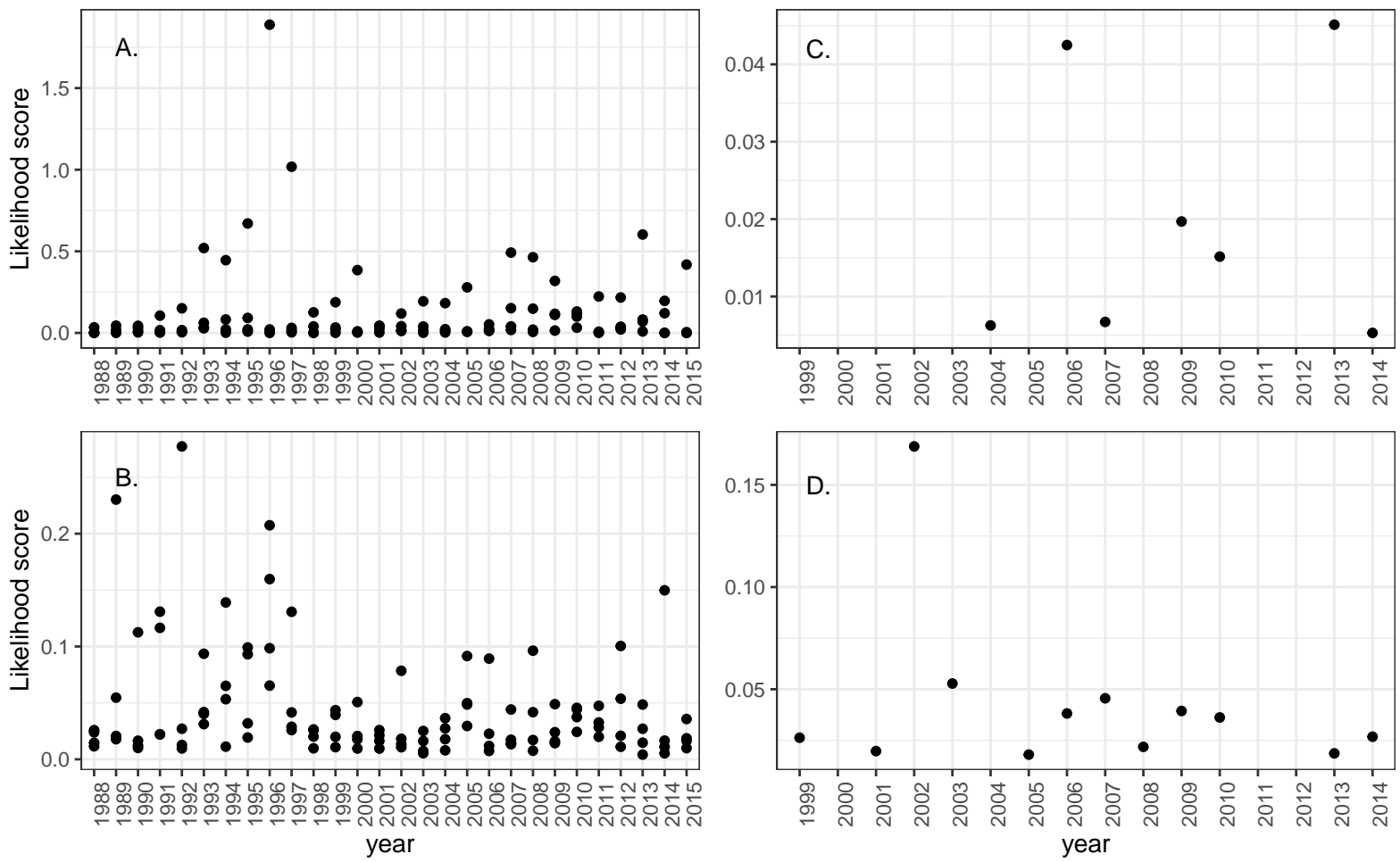

Figure 1: Likelihood scores for A. Landings age distribution, B. Landings length distribution , C. ECOCADIZ survey length distribution and D. PELAGO survey length distribution. Dots represent the score for each quarter.

Figure 2 shows the population estimates of Gadget for the time series of stock size, fishing mortality, recruitment and catch in numbers. The estimates also point to 1996 as a singular year with a remarkable change in the trend after a minimum in abundance, recruitment and catches in the year 1995. These minima coincide with the smallest signal in the time series of discharges, where years of very low discharges are followed (in 1996) by a sudden jump to high values (Figure 3.A), while the time series of wind does not show such a distinctive and abrupt event (Figure 3B). It is worth to mention here that neither discharges nor wind information were used by the Gadget model, therefore the diagnosis achieved in Figure 2 is based on fishery and survey information alone. These extreme discharge events between 1994 and 1996 could hinder the effect of other environmental variables on recruitment. Particularly for this fishery, easterly winds and discharges have been identified as the main sources of mortality before recruitment (Ruiz et al., 2006). To understand how this abrupt fluctuation of discharges could hinder the detection of wind effects, appropriate time windows were selected for Granger-causality analysis between wind and Gadget recruitment output time series: the whole time series available (1988-2009), 
and a time window where discharge signal is not so extreme (1996-2009).
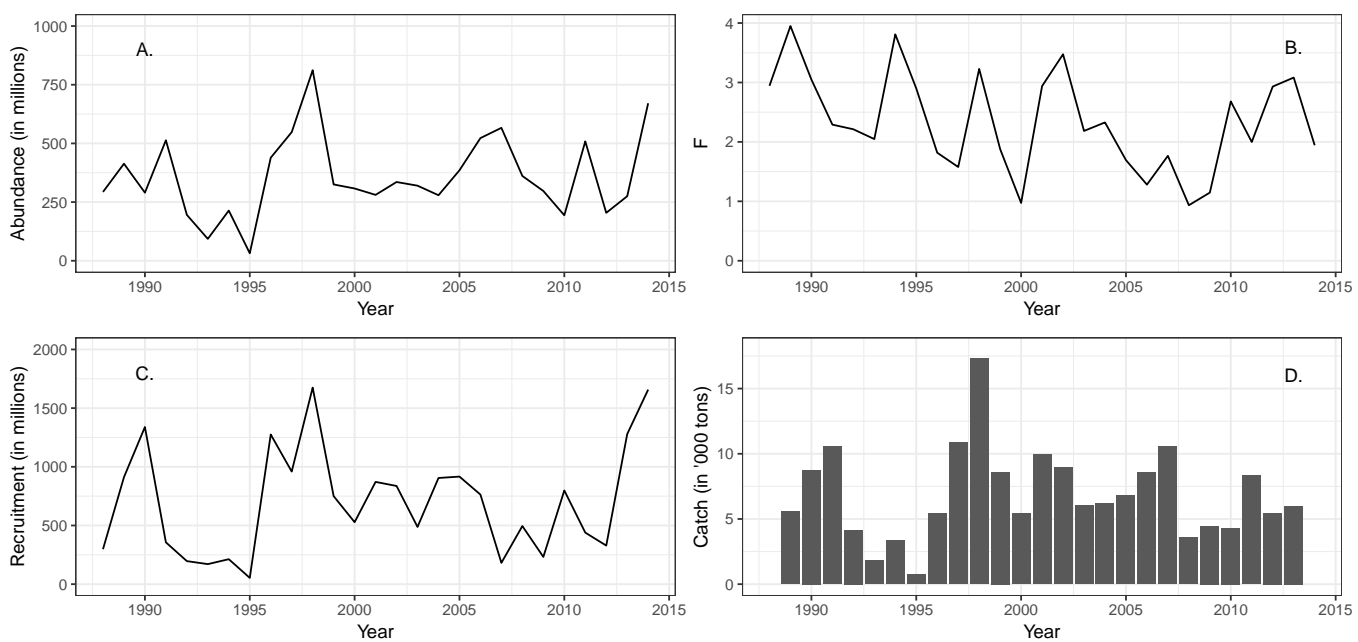

Figure 2: Gadget diagnostics: Yearly time series for A. stock size, B. recruitment, C. annual fishing mortality and D. catches.

A VAR(4) model was fitted for both time windows ( $L=4$ according to AIC criterion) and the Grangercausality test was implemented after model stability and non-serial correlation tests were passed: All eigenvalues lie inside the unit circle and there wasn't enough evidence to reject the null hypothesis of non-serial correlation. ( $H_{0}$ : No serial correlation, for time window (1988-2009): $p=0.34$ and $p=0.64$, in Portmanteau and Breusch-Godfrey test, respectively. For time window (1996-2009): $p=0.84$ and $p=0.24$, in Portmanteau and Breusch-Godfrey test, respectively).

The Wald test revealed that wind does not Granger-cause recruitment for the first time window selected ( $m=1$, Wald test for a fitted $\operatorname{VAR}(5): H_{0}^{1}, p=0.68$ and $\left.H_{0}^{2}, p=0.65\right)$ but it does for the period between 1996 and $2009\left(m=1\right.$, Wald test for a fitted $\operatorname{VAR}(5): H_{0}^{1}, p=0.045$ and $\left.H_{0}^{2}, p=0.99\right)$.

For discharges and recruitment time series, the AIC suggested that the appropriate maximum lag length $(L)$ should be 5 but the resulting $\operatorname{VAR}(5)$ model was not stable (some eigenvalues lie outside the unit circle). VAR model orders of $6,7,8$, and 9 were also tested but stability wasn't achieved. As a consequence Granger-causality test could not be implemented in those time series.

Granger-causality test for wind in the second time window provides information that is useful to forecast recruitment using the following equation from the well specified $\operatorname{VAR}(4)$ model:

$$
R_{t}=a+\alpha_{1} R_{t-1}+\alpha_{2} R_{t-2}+\cdots+\alpha_{4} R_{t-4}+\beta_{1} W_{t-1}+\beta_{2} W_{t-2}+\cdots+\beta_{L} W_{t-4}+\epsilon_{t},
$$

where $R_{t}$ and $W_{t}$ represents recruitment and wind at quarter $t$, respectively, and $a$ is a constant. 

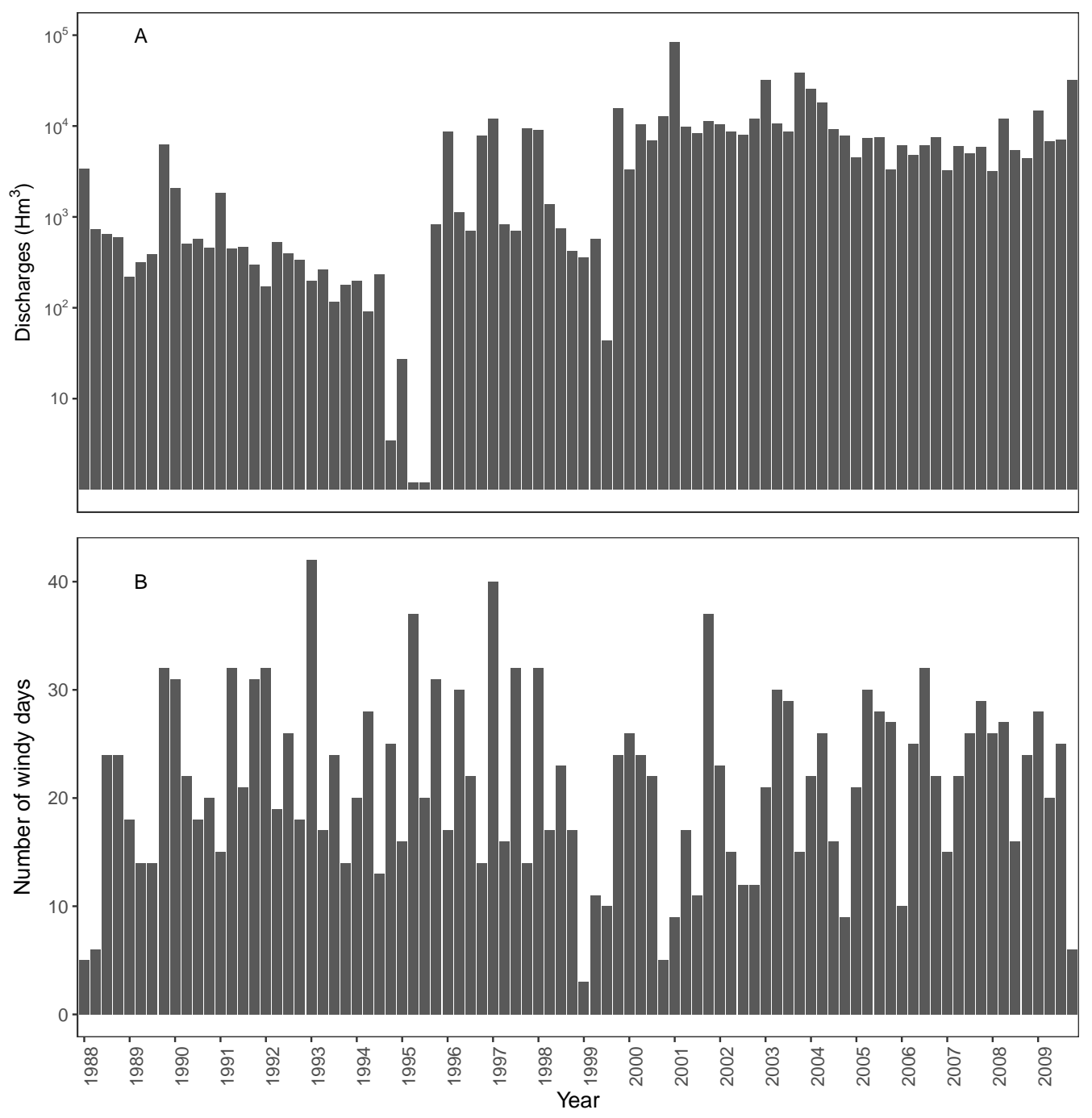

Figure 3: A. Quaterly accumulated cubic hectometers that are discharged from Alcalá del Río dam in logarithmic scale. B. Quaterly number of days with easterly winds above $30 \mathrm{Km} / \mathrm{h}$

Restricting the model to significant coefficients results in the following equation:

$$
R_{t}=a+\alpha_{4} R_{t-4}+\beta_{2} W_{t-2}+\beta_{3} W_{t-3}+\epsilon_{t},
$$

with $a=81, \alpha_{4}=0.54, \beta_{2}=6.3$ and $\beta_{3}=-6.5$ and $t=1, \ldots, 48$ corresponding to the number of quarters for 12 years.

Null hypothesis of no correlation for residuals was tested and it couldn't be rejected $(p=0.48)$. The comparison between the recruitment time series and fitted values is presented in Figure 4.

The population status was projected forward to provide a prediction of catches for 3 years into the future 


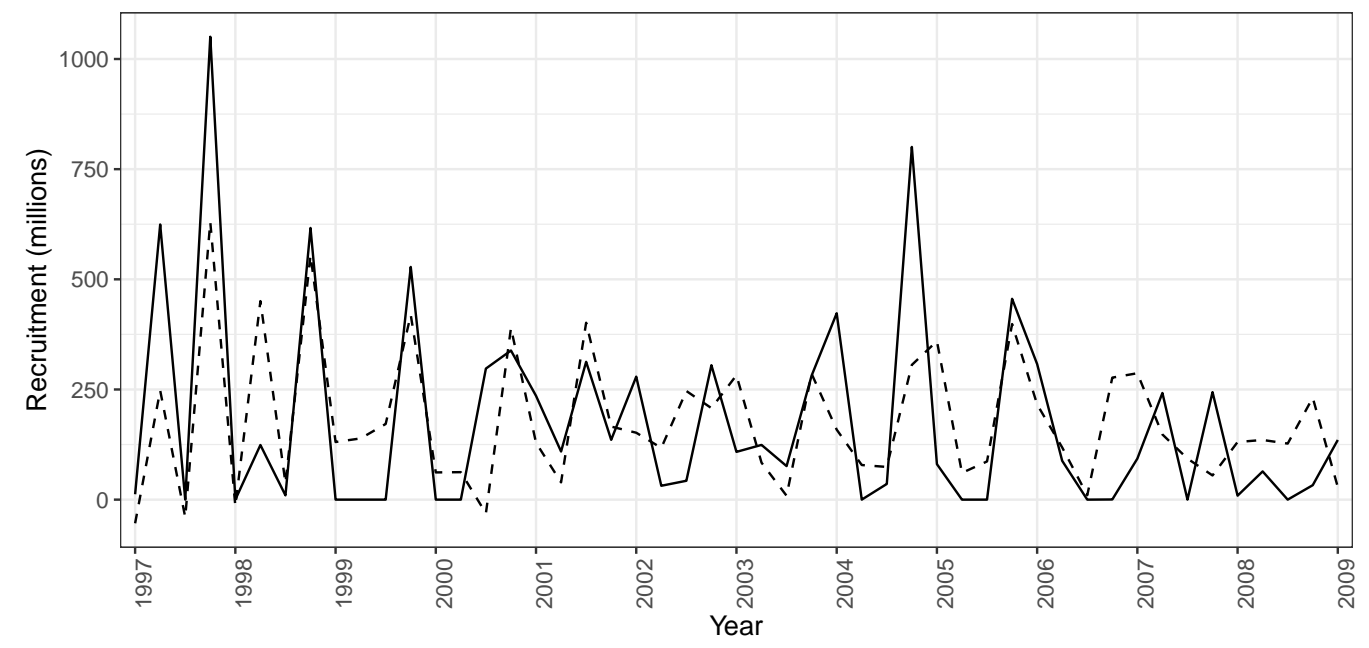

Figure 4: Comparison between Gadget recruitment output time series (solid line) and fitted values (dashed line).

(2016-2018). It was based on recruitment sampled from a normal distribution with mean

$$
R_{t^{\prime}}=a+\alpha_{4} R_{t^{\prime}-4}+\beta_{2} W_{t^{\prime}-2}+\beta_{3} W_{t^{\prime}-3}, t^{\prime}=1, \ldots, 12,
$$

and standard deviation equal to the standard deviation of the fitted model residuals $\epsilon_{t}, t=1, \ldots, 48$, where $t^{\prime}$ represent the quarters in years 2016 to 2018 , and $t$ the quarters in 1997 to 2009 . Note that $R_{t}^{\prime}, t^{\prime}=1, \ldots, 4$, were calculated using the model estimated recruitment in 2015. The values $W_{t^{\prime}}$ were assumed to illustrate two different wind scenarios. Figure 5 shows real catches (1988-2015) as well as the prediction range of 20 trajectories of projected catches (2016-2018) under a favorable (white boxes) and an adverse (grey boxes) wind scenarios. The favorable wind scenario corresponds to 10 windy days (above $30 \mathrm{Km} / \mathrm{h}$ ) in each quarter while the adverse wind scenario was designed to produce a recruitment worse than the previous year for the 3 projected years. This adverse scenario corresponds to 37 windy days in the first three quarters and in the fifth quarter (the highest quaterly wind of the historical time series), and 10 windy days in the remaining quarters. The highest differences between the good and adverse wind scenarios are found in the last two years while in the first one catches values are similar.

\section{Discussion}

Integrated models have emerged as tools suitable to assimilate in the same robust statistical framework both data on catch age-length structure and information from scientific surveys. This capacity to assimilate information of diverse nature is helpful to assess stocks through integrated models such as Gadget, which has been formally adopted as the basis for assessment of least 6 European stocks (ICES, 2017, 2016, 2014, 2013, 2012), 


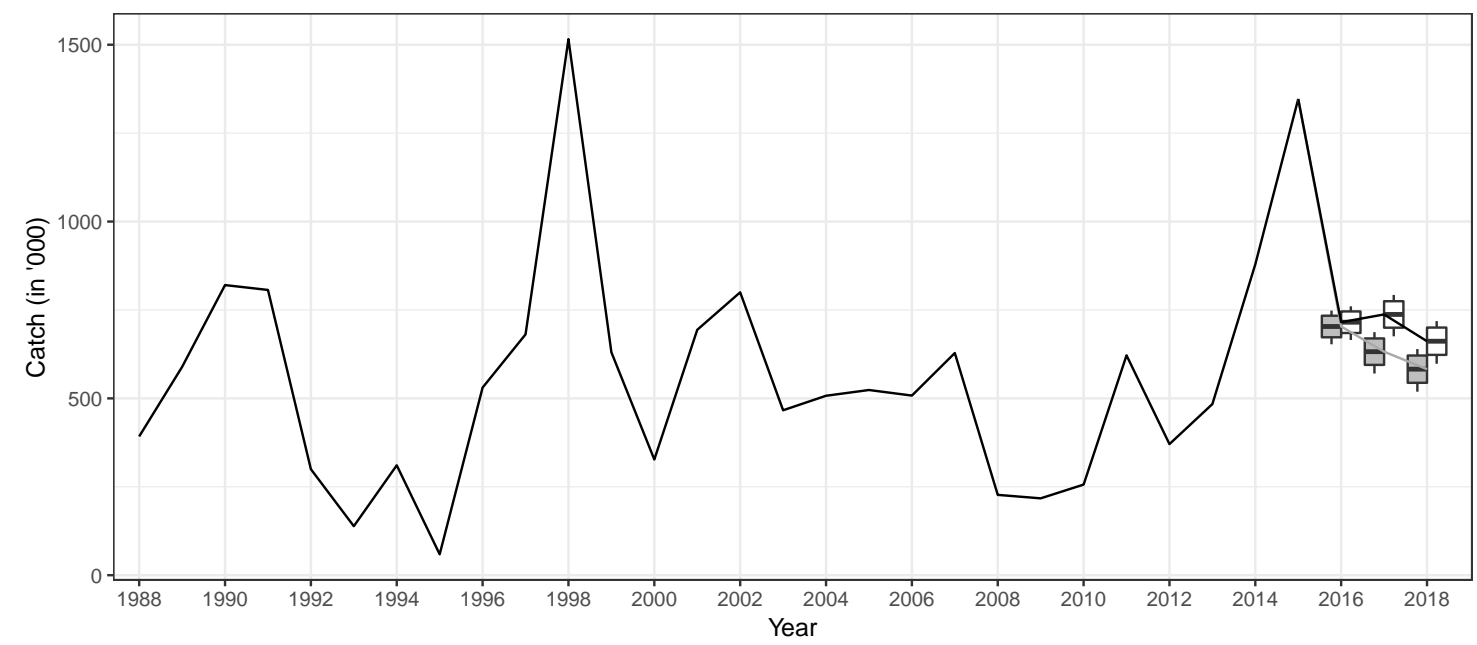

Figure 5: Real catches data (1988-2015) together with a summary of 20 trajectories of projected catches (2016-2018) under a favorable (black boxes) and an adverse (grey boxes) wind scenario using a stochastic version of the restricted model (equation 3 to forecast recruitment. Upper and lower limits of the lines outside the box account for maximum and minimum values, while the box accounts for mean and standard deviation

or SS3, which is used when assessing sixty-one stocks worldwide (Methot and Wetzel, 2013). Despite this success to coherently incorporate different types of data in the same model, integrated models do not have a standard way to include environmental effects which are known to potentially have an important role in recruitment (Lehodey et al. 2006). The understanding of key processes controlling the ecosystem is a basic requirement for the implementation of the ecosystem-based approach for fisheries management (EBFM) (Pikitch et al., 2004). Although EBFM has been formally adopted widely and a considerable amount of scientific knowledge has been established, very little of this has been utilized to support decision-making. Ecosystem drivers are actually implemented in only few fisheries management since only when there is a good understanding of ecosystem processes it might be successful to include external drivers in EBFM (Skern-Mauritzen et al., 2016).

This paper illustrates a possible path to the embedding of environmental effects through the implementation of an integrated model, Gadget, to a fishery, European anchovy in the Gulf of Cádiz, whose recruitment is known to be heavily influenced by physical forcings. The procedure starts with the first implementation of a Gadget model to the anchovy in the Gulf of Cádiz. This is achieved through the incorporation in Gadget of a large amount of length-age fishery-data since 1988 as well as numerous scientific surveys conducted in this period (Table A.2). The incorporation of such a volume of information results in an overall good estimation of age and length distributions in the diagnosed time series (Figures A.2 and A.3).

Abundance time series estimated by the Gadget model (Figure 2) are akin to previous (Bayesian) models developed for the fishery (Rincón et al. 2017) although the high volume and the diversity of information assimilated by Gadget allows narrowing the estimated range from 0-2500 millions in Rincón et al. (2017) to 0-750 millions of individuals here. In addition, Figure 2 shows high values of $\mathrm{F}$ during the years when recruitment is 
lower $(1994,2004,2007,2010)$ and the opposite, i.e. low F when recruitment is high $(1996,2011)$; in a trend that has already being identified as a consequence of the fixed quota management that puts the biology and the economy of the fishery at risk (Ruiz et al., 2017).

High $F$ and recruitment failures are concomitant features between years 1992 and 1995 . Owing to the fixed TAC and the BotTop (Ruiz et al., 2007) nature of this fishery, high $F$ can be considered as the consequence of a recruitment failure rather than the other way around. As mentioned above, the environment is known to have an important impact on the recruitment of this stock. This environmental effect can be integrated into the estimation routine of Gadget by reformulating the spawning stock biomass and recruitment relationship. However, in the present exercise, this was not done since our aim is to prove the capacity of an integrated model to estimate the existence of external forcings even before its nature is known. Therefore, our population model does not explicitly formulate the impact of environment on recruitment. Instead, key impacts of the environment, or other external drivers not explicitly formulated within the population model, force a modulation of recruitment estimates so that the integrated model keeps coherence of internal biological processes with observed fishery and survey data. In such a way, strong signals in recruitment estimates can be used to detect the presence of these external drivers that might be unknown to the modeller.

For anchovy in the Gulf of Cádiz, it is well known that these drivers are easterly winds and discharges which had conditions adverse for recruitment between 1992 and 1995 (Ruiz et al. (2006); Figure 3); these are the years when Gadget estimated recruitment failures (Figure 2). Despite this evidence, Granger-causality was unable to resolve cause-effect connections for freshwater discharges. The resulting VAR model for the estimated recruitment output and freshwater discharges, is not stable, which means that it does not generate stationary time series with time-invariant means, variances, and covariance structure; thus affecting the structural analysis and the reliability of forecasting. The nature of this signal, with a very abrupt fall in 1994-1995 (Figure 3), also seems to affect the Granger-causality analysis carried out between wind and recruitment. Causality between wind and recruitment does not appear in the whole time series, thus suggesting that the sharp signal of 1994-1995 discharges could hinder the effect of the wind at the Granger-causality analysis. This interpretation is supported by previous analysis where wind results as the main source of variability for population size (Rincón et al. 2016) and the very good agreement between the mathematical formulation for recruitment (Equation 3) and Gadget estimations in a time period that does not includes those years (Figure 4).

Although the positive output of the Granger-causality test between wind and recruitment does not exclude the existence of other external drivers of recruitment, the concordance shown by Figure 4 indicates that wind could be used for fishery management when discharge signal is not dominant, i. e. in years when a severe drought results in very low river discharges. Thus, despite the significant limitations that these sharp signals seem to bring to Granger-causality analyses, the implementation of this technique for the period between 1997 
and 2009 confirms the importance of wind to predict recruitment. Granger-causality analysis in this time slice provides a simple mathematical structure (Equation 3) to predict recruitment and, therefore, to support in management. This structure was used here, to assess different wind scenarios in Figure 5 as an example of how these simple expressions can help decision-makers to assess the consequences of their decisions under different climatic conditions. For example, one of the possible bad scenarios presented here suggests that three successive quarters in a year plus the first quarter in the next year with a high frequency of strong winds could gradually reduce recruitment. Some additional exploration in this direction could be interesting to determine all possible combinations that could increase the collapse probability.

In summary, this paper presents a procedure to predict external forcings on a fishery through the implementation of an integrated model and the analysis of its output recruitment. Gadget has successfully been set up to detect the recruitment failure whose origin is known to be in environmental forcing. The subsequent analysis of causality by Granger techniques has only partially been successful since it did not work for the sharp signal associated with the effect of discharges on recruitment. However, Granger-causality has clearly identified the important role of wind in conditioning recruitment for non-drought years and has provided simple formulations that are transparent and easy to implement in a decision-making frame.

Although it is difficult to find in nature that the variation in one variable is totally caused by another, and this Granger-causality test between wind and recruitment does not exclude the effect of other unknown environmental variables on recruitment, for the last years, Granger-Causality goes beyond correlation confirming the importance of wind to predict recruitment. It suggests that wind data is useful in the management of anchovy and gives a simple mathematical structure to implement when testing management strategies.

\section{Acknowledgements}

The research leading to these results has received funding from the European Union Seventh Framework Programme (FP7-KBBE-2013) under the grant agreement 613571/MAREFRAME project and Margarita M. Rincón was funded by P09-RNM-5358 of the Junta de Andalucía and CEIJ-018, CEIMAR young researchers project. However, the paper does not necessarily reflect EC views and in no way anticipates the Commission's future policy in the area. We would also like to thank Jamie Lentin from Shuttlethread for his tireless efforts in automating data collection and the creation of input files for Gadget.

Further we gratefully thank CESGA (Galician Supercomputing Center) for computational time at SVG and Finisterrae II supercomputers and technical assistance. 


\section{References}

A. Myers, R., Mertz, G., 1998. Reducing uncertainty in the biological basis of fisheries management by metaanalysis of data from many populations: a synthesis. Fisheries Research 37, 51-60. URL: http://www . sciencedirect.com/science/article/pii/S016578369800126X, doi:10.1016/S0165-7836(98)00126-X.

Akaike, H., 1974. A New Look at the Statistical Model Identification, in: Selected Papers of Hirotugu Akaike. Springer, New York, NY. Springer Series in Statistics, pp. 215-222. URL: https://link.springer.com/ chapter/10.1007/978-1-4612-1694-0_16, doi 10.1007/978-1-4612-1694-0_16

Akaike, H., 1998. Information Theory and an Extension of the Maximum Likelihood Principle, in: Selected Papers of Hirotugu Akaike. Springer, New York, NY. Springer Series in Statistics, pp. 199-213. URL: https: //link.springer.com/chapter/10.1007/978-1-4612-1694-0_15, doi 10.1007/978-1-4612-1694-0_15

Bartolino, V., Colloca, F., Taylor, L., Stefansson, G., 2011. First implementation of a gadget model for the analysis of hake in the mediterranean. Fisheries research 107, 75-83.

Begley, J., 2004. Gadget User Guide. URL: http://www.hafro.is/gadget/files/userguide.pdf.

Begley, J., Howell, D., 2004. An overview of Gadget, the globally applicable area-disaggregated general ecosystem toolbox, ICES. URL: https://brage.bibsys.no/xmlui/handle/11250/100625

Bellido, J.M., Pierce, G.J., Romero, J.L., Millan, M., 2000. Use of frequency analysis methods to estimate growth of anchovy ( $<\mathrm{i}>$ Engraulis encrasicolus $</ \mathrm{i}>$ L. 1758) in the Gulf of Cádiz (SW Spain). Fisheries Research 48, 107-115. URL: http://www.sciencedirect.com/science/article/pii/S0165783600001831.

Berkeley, G., Krauth, C.P., 1874. A Treatise Concerning the Principles of Human Knowledge. J. B. Lippincott \& Company. Google-Books-ID: 3PceAAAAMAAJ.

Breusch, T.S., 1978. Testing for autocorrelation in dynamic linear models. Australian Economic Papers 17, $334-355$.

Caputi, N., 1988. Factors Affecting the Time Series Bias in Stock-Recruitment Relationships and the Interaction Between Time Series and Measurement Error Bias. Can. J. Fish. Aquat. Sci. 45, 178-184. URL: http: //www.nrcresearchpress.com/doi/abs/10.1139/f88-019, doi:10.1139/f88-019.

Demyanov, V., Wood, S.N., Kedwards, T.J., 2006. Improving ecological impact assessment by statistical data synthesis using process-based models. Journal of the Royal Statistical Society: Series C (Applied Statistics) 55, 41-62. URL: http://onlinelibrary.wiley.com/doi/10.1111/j.1467-9876.2005.00527.x/abstract, doi $10.1111 / \mathrm{j} .1467-9876.2005 .00527 . \mathrm{x}$ 
Deriso, R.B., Quinn II, T.J., Neal, P.R., 1985. Catch-Age Analysis with Auxiliary Information. Canadian Journal of Fisheries and Aquatic Sciences 42, 815-824. URL: http://www.nrcresearchpress.com/doi/abs/ 10.1139/f85-104, doi $10.1139 /$ f85-104.

Elvarsson, B.m., Woods, P.J., Björnsson, H., Lentin, J., Thordarson, G., 2018. Pushing the limits of a data challenged stock: A size-and age-structured assessment of ling (molva molva) in icelandic waters using gadget. Fisheries Research 207, 95-109.

Elvarsson, B., Taylor, L., Trenkel, V., Kupca, V., Stefansson, G., 2014. A bootstrap method for estimating bias and variance in statistical fisheries modelling frameworks using highly disparate datasets. African Journal of Marine Science 36, 99-110. URL: http://www.tandfonline.com/doi/abs/10.2989/1814232X.2014.897253, doi:10.2989/1814232X.2014.897253.

Elvarsson, B.T., Lentin, J., 2016. Rgadget: R package for Gadget models. R package version 0.5.

Foresti, P., 2006. Testing for Granger causality between stock prices and economic growth URL: https://mpra. ub.uni-muenchen.de/2962

Fournier, D., Archibald, C.P., 1982. A General Theory for Analyzing Catch at Age Data. Canadian Journal q of Fisheries and Aquatic Sciences 39, 1195-1207. URL: http://www.nrcresearchpress.com/doi/abs/10. 1139/f82-157, doi:10.1139/f82-157

Gilbert, D.J., 1997. Towards a new recruitment paradigm for fish stocks. Canadian Journal of Fisheries and Aquatic Sciences 54, 969-977. URL: http://www.nrcresearchpress.com/doi/abs/10.1139/f96-272.

Giráldez, A., Torres, P., Quintanilla, L.F., Bellido, J., Alemany, F., Iglesias, M., 2009. Anchovy (Engraulis encrasicolus) Stock Assessment in the GFCM Geographical Sub-Area 01. Northern Alboran Sea. Technical Report. GFCM-SCSA. Working group on small pelagics.

Godfrey, L.G., 1978. Testing for higher order serial correlation in regression equations when the regressors include lagged dependent variables. Econometrica: Journal of the Econometric Society, 1303-1310.

González-Ortegón, E., Drake, P., 2012. Effects of freshwater inputs on the lower trophic levels of a temperate estuary: physical, physiological or trophic forcing? Aquatic Sciences 74, 455-469. URL: http://link. springer.com/10.1007/s00027-011-0240-5, doi:10.1007/s00027-011-0240-5.

González-Ortegón, E., Subida, M., Cuesta, J., Arias, A., Fernández-Delgado, C., Drake, P., 2010. The impact of extreme turbidity events on the nursery function of a temperate European estuary with regulated freshwater inflow. Estuarine, Coastal and Shelf Science 87, 311-324. URL: http://linkinghub.elsevier.com/ retrieve/pii/S0272771410000284, doi $10.1016 / \mathrm{j}$. ecss.2010.01.013 
Granger, C.W.J., 1969. Investigating Causal Relations by Econometric Models and Cross-spectral Methods. Econometrica 37, 424-438. URL: http://www.jstor.org/stable/1912791, doi 10.2307/1912791.

He, Z., Maekawa, K., 2001. On spurious Granger causality. Economics Letters 73, 307-313. URL: http: //wWw.sciencedirect.com/science/article/pii/S0165176501004980.

ICES, 2012. Report of the Benchmark Workshop on Redfish (WKRED 2012). Technical Report. 1-8 February 2012, Copenhagen, Denmark. ICES CM 2012/ACOM:48.

ICES, 2013. Report of the Working Group on the Assessment of Southern Shelf Stocks of Hake, Monk and Megrim (WGHMM). Technical Report. 10 - 16 May 2013, ICES Headquarters, Copenhagen. ICES CM 2013/ACOM:11A.

ICES, 2014. Report of the Workshop on Redfish Management Plan Evaluation (WKREDMP). Technical Report. 20-25 January, Copenhagen, Denmark. ICES CM 2014/ACOM:52.

ICES, 2016. Report of the Workshop on Assessment and Catch Advice for Deep Pelagic Redfish in the Irminger Sea (WKDEEPRED). Technical Report. 23-25 August 2016, ICES HQ, Copenhagen, Denmark. ICES CM 2016/ACOM:52.

ICES, 2017. Report of the Workshop on Evaluation of the Adopted Harvest Control Rules for Icelandic Summer Spawning Herring, Ling and Tusk (WKICEMSE). Technical Report. 21-25 April 2017, Copenhagen, Denmark. ICES CM 2017/ACOM:45.

Lehodey, P., Alheit, J., Barange, M., Baumgartner, T., Beaugrand, G., Drinkwater, K., Fromentin, J.M., Hare, S.R., Ottersen, G., Perry, R.I., 2006. Climate variability, fish, and fisheries. Journal of Climate 19, 5009-5030.

Lentin, J., 2014. mfdb: MareFrame DB Querying Library. R package version 3.2-0.

Lesnoff, M., Lancelot, R., 2012. aod: Analysis of Overdispersed Data. URL: http://cran.r-project.org/ package=aod, r package version 1.3.

Lütkepohl, H., 2013. Introduction to Multiple Time Series Analysis. Springer Berlin Heidelberg. URL: https: //books.google.es/books?id=qJXsCAAAQBAJ

Masih, R., Masih, A.M., 1996. Macroeconomic activity dynamics and Granger causality: New evidence from a small developing economy based on a vector error-correction modelling analysis. Economic Modelling 13, 407-426. URL: http://www.sciencedirect.com/science/article/pii/0264999396010139 
Maunder, M.N., Punt, A.E., 2013. A review of integrated analysis in fisheries stock assessment. Fisheries

Methot, R.D., 1989. Synthetic estimates of historical abundance and mortality for northern anchovy, in: Am. Fish. Soc. Symp, pp. 66-82. URL: http://swfsc.noaa.gov/publications/cr/1989/8944.pdf.

Methot, R.D., Wetzel, C.R., 2013. Stock synthesis: A biological and statistical framework for fish stock assessment and fishery management. Fisheries Research 142, 86-99. URL:http://linkinghub.elsevier.com/retrieve/ pii/S0165783612003293, doi $10.1016 / j . f i s h r e s .2012 .10 .012$.

Millán, M., 1999. Reproductive characteristics and condition status of anchovy Engraulis encrasicolus L. from the 17 Bay of Cadiz (SW Spain). Fisheries Research 41, 73-86. URL: http://www.sciencedirect.com/science/ article/pii/S0165783699000107, doi:10.1016/S0165-7836(99)00010-7.

Mookerjee, R., Yu, Q., 1997. Macroeconomic variables and stock prices in a small open economy: The case घ of Singapore. Pacific-Basin Finance Journal 5, 377-388. URL: http://www.sciencedirect.com/science/ article/pii/S0927538X96000297.

Peliz, A., Boutov, D., Cardoso, R.M., Delgado, J., Soares, P.M., 2013. The gulf of cadiz-alboran sea sub-basin: Model setup, exchange and seasonal variability. Ocean Modelling 61, 49 - 67. URL: http:

//www.sciencedirect.com/science/article/pii/S1463500312001527, doi:https://doi.org/10.1016/j. ocemod.2012.10.007

Pfaff, B., 2008. VAR, SVAR and SVEC Models: Implementation Within $R$ Package vars. Journal of Statistical Software 27. URL: http://www.jstatsoft.org/v27/i04/, doi:10.18637/jss.v027.i04

Pikitch, E., Santora, C., Babcock, E., Bakun, A., Bonfil, R., Conover, D., Dayton, P., others, Doukakis, P., Fluharty, D., Heneman, B., et al., 2004. Ecosystem-based fishery management.

Relvas, P., Barton, E.D., 2002. Mesoscale patterns in the cape sao vicente (iberian peninsula) upwelling region. Journal of Geophysical Research: Oceans 107, 28-1.

Rincón, M.M., Catalán, I.A., Mäntyniemi, S., Macías, D., Ruiz, J., $2017 . \quad$ Embedding the effect of environmental conditions on recruitment and survival of the European anchovy (Engraulis encrasicolus): a Bayesian model with dual-time resolution. Fish口 ery Bulletin 116, 34-49. URL: https://spo.nmfs.noaa.gov/content/fishery-bulletin/ embedding-effect-environmental-conditions-recruitment-and-survival-european, doi:10.7755/ FB.116.1.4 
Rincón, M.M., Mumford, J.D., Levontin, P., Leach, A.W., Ruiz, J., 2016. The economic value of environmental 1 data: a notional insurance scheme for the European anchovy. ICES J. Mar. Sci. , fsv268URL: http://icesjms . oxfordjournals.org/content/early/2016/01/26/icesjms.fsv268, doi:10.1093/icesjms/fsv268

Ruiz, J., Garcia-Isarch, E., Emma Huertas, I., Prieto, L., Juárez, A., Muñoz, J., Sánchez-Lamadrid, A., Rodríguez-Gálvez, S., Naranjo, J., Baldó, F., 2006. Meteorological and oceanographic factors influencing Engraulis encrasicolus early life stages and catches in the Gulf of Cádiz. Deep Sea Research Part II: Topical Studies in Oceanography 53, 1363-1376.

Ruiz, J., Gonzáles-Quirós, R., Prieto, L., García Lafuente, J., 2007. Anchovy in the Gulf of Cádiz: a case of BOTTOP control. GLOBEC International Newsletter URL: http://www.academia.edu/7514598/Anchovy_ in_the_Gulf_of_C\%C3\%A1diz_a_case_of_BOTTOP_control.

Ruiz, J., González-quirós, R., Prieto, L., Navarro, G., 2009. A Bayesian model for anchovy (Engraulis encrasicolus): the combined forcing of man and environment. Fisheries Oceanography 18, 62-76. URL: http://onlinelibrary.wiley.com/doi/10.1111/j.1365-2419.2008.00497.x/abstract, doi:10.1111/j. $1365-2419.2008 .00497 . x$

Ruiz, J., Rincón, M.M., Castilla, D., Ramos, F., del Hoyo, J.J.G., 2017. Biological and economic vulnerabilities of fixed TACs in small pelagics: An analysis of the European anchovy (Engraulis encrasicolus) in the Gulf of Cádiz. Marine Policy 78, 171-180. URL: http://linkinghub.elsevier.com/retrieve/pii/ S0308597X16303852, doi:10.1016/j.marpol.2017.01.022

Sims, C.A., 1972. Money, Income, and Causality. The American Economic Review 62, 540-552. URL: http: //www.jstor.org/stable/1806097.

Skern-Mauritzen, M., Ottersen, G., Handegard, N.O., Huse, G., Dingsør, G.E., Stenseth, N.C., Kjesbu, O.S., 2016. Ecosystem processes are rarely included in tactical fisheries management. Fish and Fisheries 17, 165-175.

Stefansson, G., 2003. Issues in Multispecies Models. Natural Resource Modeling 16, 415-437. URL: http://onlinelibrary.wiley.com/doi/10.1111/j.1939-7445.2003.tb00121.x/abstract, doi:10.1111/ j.1939-7445.2003.tb00121.x.

Stefansson, G., 2005. Growth models in population simulations. In: Final Report. dst2 : Development of structurally detailed statistically testable models of marine populations. Technical Report 118. pp $73-83$. Technical Report. Marine Research Institute, Reykjavik. 
Stefánsson, G., 1998. Comparing different information sources in a multispecies context. Fishery stock assessment models. Alaska Sea Grant College Program. AK-SG-98-01, 741-758URL: http://mdgs.un.org/unsd/ envaccounting/ceea/archive/Fish/Iceland.PDF.

Stern, D.I., Kaufmann, R.K., 2014. Anthropogenic and natural causes of climate change. Climatic change 122, 257-269. URL: http://link.springer.com/article/10.1007/s10584-013-1007-x.

Sugihara, G., May, R., Ye, H., Hsieh, C.h., Deyle, E., Fogarty, M., Munch, S., 2012. Detecting Causality in Complex Ecosystems. Science 338, 496-500. URL: http://www.sciencemag.org/cgi/doi/10.1126/science. 1227079, doi:10.1126/science.1227079

Taylor, L., Begley, J., Kupca, V., Stefansson, G., 2007. A simple implementation of the statistical modelling framework Gadget for cod in Icelandic waters. African Journal of Marine Science 29, 223-245. URL: http: //www.tandfonline.com/doi/abs/10.2989/AJMS.2007.29.2.7.190, doi10.2989/AJMS.2007.29.2.7.190

„Tedds, L.M., Giles, D.E., 2002. Taxes and the Canadian underground economy URL: https://papers.ssrn. com/sol3/papers.cfm?abstract_id=1002475

Toda, H.Y., Yamamoto, T., 1995. Statistical inference in vector autoregressions with possibly integrated processes. Journal of Econometrics 66, 225-250. URL: http://www.sciencedirect.com/science/article/pii/ 0304407694016168, doi $10.1016 / 0304-4076(94) 01616-8$.

Walters, C.J., 1985. Bias in the Estimation of Functional Relationships from Time Series Data. Can. J. Fish. 口 Aquat. Sci. 42, 147-149. URL: http://www.nrcresearchpress.com/doi/abs/10.1139/f85-018, doi 10. $1139 / f 85-018$.

Xie, Y., 2014. knitr: a comprehensive tool for reproducible research in R. Implement Reprod Res 1, 20. URL: https://books.google.es/books?hl=en\&lr=\&id=WVTSBQAAQBAJ\&oi=fnd\&pg=PA3\&dq=Yihui+Xie+ (2014)+knitr:+A+Comprehensive\&ots=qREu7cFlT2\&sig=8PdOHWGYj-o8vYvamTNRg7JwEzE

Ye, Y., 2000. Is recruitment related to spawning stock in penaeid shrimp fisheries? ICES Journal of Marine 口 Science 57, 1103-1109. URL: https://academic.oup.com/icesjms/article-lookup/doi/10.1006/jmsc. 2000.0706 doi $10.1006 /$ jmsc.2000.0706

Yule, G.U., 1926. Why do we Sometimes get Nonsense-Correlations between Time-Series?-A Study in Sampling n and the Nature of Time-Series. Journal of the Royal Statistical Society 89, 1-63. URL: http://www.jstor. org/stable/2341482, doi:10.2307/2341482 
Zombe, C., Daka, L., Phiri, C., Kaonga, O., Chibwe, F., Seshamani, V., 2017. Investigating the Causal Relationship between Inflation and Trade Openness using Toda-Yamamoto Approach: Evidence from Zambia. Mediterranean Journal of Social Sciences 8. URL: http://www.degruyter.com/view/j/mjss.2017.8. issue-6/mjss-2017-0054/mjss-2017-0054.xml, doi 10.1515/mjss-2017-0054.

\section{A. Appendix: Model description}

The general Gadget model description and all the options available can be found in Gadget manual (Begley, 2004) and some specific examples can be found in Taylor et al. (2007) and Elvarsson et al. (2014). The Gadget model implementation consists in three parts, a simulation of biological dynamics of the population (simulation model), a fitting of the model to observed data using a weighted log-likelihood function (observation model) and the optimization of the parameters using different iterative algorithms.

A list of symbols used, a summary of the real data included and a graph with the Gadget model structure are presented in Tables A. A.2 and Figure A.1. respectively.

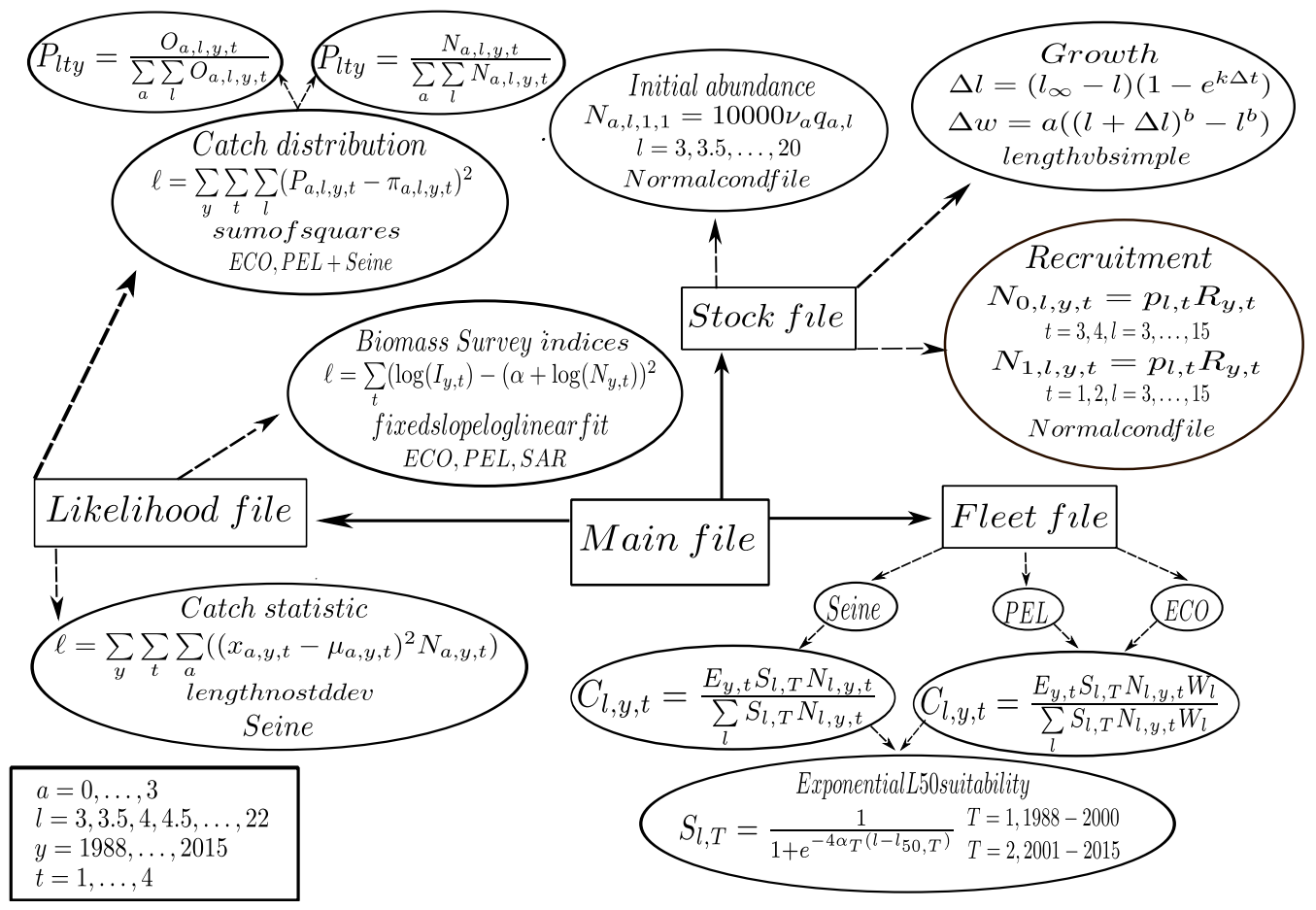

Figure A.1: Graph Gadget model

\section{A.1. Simulation model}

The model consists of one stock component of anchovy (Engraulis encrasicolus) in the ICES subdivision 9a South, South-Atlantic Iberian waters, Gulf of Cádiz. Gadget works by keeping track of the number of individuals, 


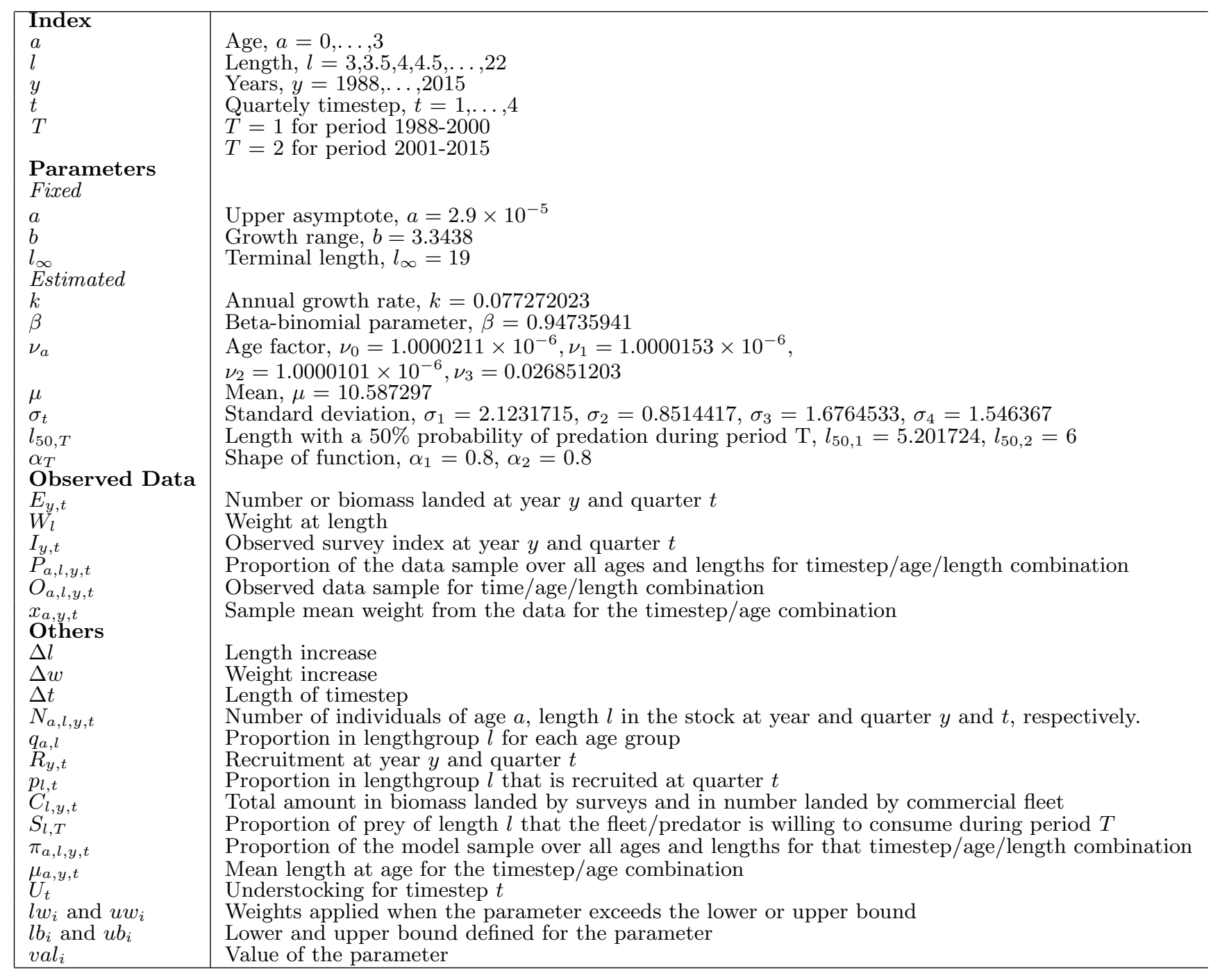

Table A.1: List of Symbols used in model specification

$N_{a, l, y, t}$, at age $a=0, \ldots, 3$, at length $l=3,3.5,4,4.5, \ldots, 22$, at year $y=1988, \ldots, 2015$, and each year divided into quarters $t=1, \ldots, 4$. The last time step of a year involves increasing the age by one year, except for the last age group, which its age remains unchanged and the age group next to is added to it, like a 'plus group' including all ages from the oldest age onwards (Taylor et al., 2007).

\section{Growth}

The growth function is a simplified version of the Von Bertalanffy growth equation, defined in Begley (2004) as the LengthVBSimple Growth Function (lengthvbsimple). Length increase for each length group of the stock is given by the equation below:

$$
\Delta l=\left(l_{\infty}-l\right)\left(1-e^{k \Delta t}\right),
$$


where $\Delta t$ is the length of the timestep, $l_{\infty}=19 \mathrm{~cm}$ is the terminal length and $k$ is the growth rate parameter. The corresponding increase in weight of the stock is given by:

$$
\Delta w=a\left((l+\Delta l)^{b}-l^{b}\right),
$$

with $a=2.9 e^{-5}$ and $b=3.3438$ set as fixed and extracted from Millán (1999). The growth functions described above calculate the mean growth for the stock within the model. In a second step the growth is translated into a beta-binomial distribution of actual growths around that mean with a parameter $\beta$ to be fitted by the model as described in Taylor et al. (2007).

\section{Initial abundance and recruitment}

Stock population in numbers at the starting point of the simulation is defined as:

$$
N_{a, l, 1,1}=10000 \nu_{a} q_{a, l}, \quad a=0, \ldots, 3, l=3, \ldots, 20
$$

Where $\nu_{a}$ is an age factor to be calculated by the model and $q_{a, l}$ is the proportion at lengthgroup $l$ that is determined by a normal density with a specified mean length and standard deviation for each age group. Mean length at age and standard deviation was extracted from the age-length key calculated with Powell-Weterall methods in Bellido et al. (2000), the standard deviation was chosen as the same for all age groups and equal to the maximum standard deviation (1.5). The mean weight at age for this initial population is calculated by multiplying the reference weight corresponding to the length by a relative condition factor assumed as 1 . Reference weight at length $l=3,3.5, \ldots, 20$ was approximated with an exponential fit $\left(w=6.74 e^{-4} e^{0.23 * l}\right)$ using data from length at age (Seasonal Von Bertallanfy growth Bellido et al. (2000)) and transforming them to weight with the formula $w=a l^{b}, a=0.0038$ and $b=3.19$ for individuals from 1-10 months old and $a=2.9 e^{-5}, b=3.3438$, for individuals older than 10 months (Millán, 1999). In Gadget files this was specified as a normal condition distribution (Normalcondfile).

Similarly to the process to calculate the initial abundance described above, the recruitment specifies how the stock will be renewed. Recruits for $t=3,4$ and $t=1,2$ enter to the age 0 and age 1 population, respectively, as follows:

$$
N_{0, l, y, t}=p_{l, t} R_{y, t}, \quad t=3,4, l=3, \ldots, 15,
$$

and

$$
N_{1, l, y, t}=p_{l, t} R_{y, t}, \quad t=1,2, l=3, \ldots, 15,
$$

where $R_{y, t}$ represents recruitment at year $y$ and quarter $t$, and $p_{l, t}$ the proportion in lengthgroup $l$ that is recruited 
at quarter $t$ which is sampled from a normal density with mean $(\mu)$ and standard deviation $\left(\sigma_{t}\right)$ calculated by the model. The mean weight for these recruits is calculated by multiplying the reference weight corresponding to the length by a relative condition factor assumed as 1 . Reference weight at age was the same used to calculate the initial population mean weight at age explained above. In gadget files this was specified also as a normal condition distribution (Normalcondfile).

\section{Natural mortality}

In the simulation, natural mortality is simply modelled as the proportion of the stock that is removed due to these additional causes from each age group, on each timestep, as follows:

$$
N_{a}=e^{-M_{a} \Delta t},
$$

where $M_{a}$ represents natural mortality at age. In the model it was assumed as constant with $M_{0}=1.17$ and $M_{1}=0.43$. These values were derived from anchovy mortality in the Alboran Sea (Giráldez et al., 2009) while the values for $M_{2}$ and $M_{3}$ were chosen high enough to be consistent with catches at age data, where individuals older than two years are rarely found.

\section{Fleet operations}

In the model the fleets act as predators. There are three fleets inside the model: two for acoustic surveys (ECOCADIZ and PELAGO) and one for commercial landings (purse-seine fleet). Acoustic surveys fleets are assumed to remove $1 \mathrm{Kg}$ in each of the quarters when the surveys take place. Commercial fleet is assumed to remove a number of individuals each quarter based on reported total landings (extracted from ICES reports). Catches are simulated based on these data available for the fleets and a length based suitability function that splits the total amount landed by surveys (in biomass, totalfleet) and the commercial fleet (in numbers, numberfleet) between the length groups, according to equations A.4 and A.5 respectively, as follows:

$$
C_{l, y, t}=\frac{E_{y, t} S_{l, T} N_{l, y, t} W_{l}}{\sum_{l} S_{l, T} N_{l, y, t} W_{l}},
$$

and

$$
C_{l, y, t}=\frac{E_{y, t} S_{l, T} N_{l, y, t}}{\sum_{l} S_{l, T} N_{l, y, t}},
$$

where $E_{y, t}$ represents biomass landed (in $K g$ ) at year $y$ and quarter $t$ in equation A.4 and numbers landed in equation A.5 $W_{l}$ corresponds to weight at length and $S_{l, T}$ represents the suitability function that determines the proportion of prey of length $l$ that the fleet is willing to consume during period $T, T=1,2$, where $T=1$ 
corresponds to the period $1988-2000$ and $T=2$ to $2001-2015$. Splitting the suitability into these two periods corresponds to minimum landing size restrictions effectively applied to the fishery from 2001.

For this model the suitability function is specified in Gadget manual as an ExponentialL50 function (expsuitfuncl50), and it is defined as follows:

$$
S_{l, T}=\frac{1}{1+e^{-4 \alpha_{T}\left(l-l_{50, T}\right)}}
$$

where $l_{50, T}$ is the length of the prey with a $50 \%$ probability of predation during period $\mathrm{T}$ and $\alpha_{T}$ a parameter related to the shape of the function, both parameters are estimated from the data within the Gadget model. The whole model time period (1988-2015) has been splited into two different periods for suitability parameters because of changes in in minimum landing size regulation for the fishery around 1995 that become effective around 2001.

\section{A.2. Observation model}

Data are assimilated by Gadget using a weighted log-likelihood function. The model uses as likelihood components three biomass survey indices (ECOCADIZ, PELAGO and SAR), age - length distributions from two surveys (ECOCADIZ and PELAGO) and one commercial fleet (purse-seine) and mean length at age distribution from that commercial fleet (see Table A.2 for an overview of the likelihood data used in the model).

\begin{tabular}{|c|c|c|c|}
\hline Data source & type & Timespan & Likelihood function \\
\hline \multirow{3}{*}{ Commercial landings } & Length distribution & All quarters, 1988-2015 & See eq. A.8 \\
\hline & Age distribution & All quarters, 1988-2015 & See eq. $\overline{A .8}$ \\
\hline & Mean length at age of landings & All quarters, $1988-2015$ & See eq. A.11 \\
\hline \multirow[t]{2}{*}{ ECOCADIZ survey } & Biomass survey indexes & $\begin{array}{l}\text { Second quarter 2004, } 2006 \\
\text { third quarter } 2007,2009,2010,2013 \text { and } 2014\end{array}$ & see eq. A.7 \\
\hline & Age-length distribution & $\begin{array}{l}\text { Second quarter 2004, 2006 } \\
\text { third quarter 2007, 2009, 2010, } 2013 \text { and } 2014\end{array}$ & see eq. \\
\hline \multirow[t]{2}{*}{ PELAGO survey } & Biomass survey indexes & $\begin{array}{l}\text { First quarter 1999, 2001-2003 } \\
\text { second quarter 2005-2010 and } 2014\end{array}$ & see eq. [ \\
\hline & Age-length distribution & $\begin{array}{l}\text { First quarter 1999, 2001-2003 } \\
\text { second quarter 2005-2010, } 2013 \text { and } 2014\end{array}$ & see eq. \\
\hline SAR survey & Biomass survey indexes & Last quarter 1998, 2000,2001, 2007 and 2012 & see eq. A.7 \\
\hline
\end{tabular}

Table A.2: Overview of the likelihood data used in the model

\section{Biomass Survey indices}

The survey indices are defined as the total biomass of fish caught in a survey. The survey index is compared to the modelled abundance using a log linear regression with slope equal to 1 (fixedslopeloglinearfit), as follows:

$$
\ell=\sum_{t}\left(\log \left(I_{y, t}\right)-\left(\alpha+\log \left(N_{y, t}\right)\right)^{2}\right.
$$


where $I_{y, t}$ is the observed survey index at year $y$ and quarter $t$ and $N_{y, t}$ is the corresponding population abundance calculated within the model. Note that the intercept of the $\log$-linear regression, $\alpha=\log (q)$, with $q$ as the catchability of the fleet (i.e $I_{y, t}=q N_{y, t}$ ).

\section{Catch distribution}

Age-length distributions are compared using $l$ lengthgroup at age $a$ and time-step $y, t$ for both, commercial and survey fleets with a sum of squares likelihood function (sumofsquares):

$$
\ell=\sum_{y} \sum_{t} \sum_{l}\left(P_{a, l, y, t}-\pi_{a, l, y, t}\right)^{2}
$$

where $P_{a, l, t, y}$ is the proportion of the data sample for that time/age/length combination, while $\pi_{a, l, t, y}$ is the proportion of the model sample for the same combination, as follows:

$$
P_{a, l, t, y}=\frac{O_{a, l, y, t}}{\sum_{a} \sum_{l} O_{a, l, y, t}}
$$

and

$$
\pi_{a, l, t, y}=\frac{N_{a, l, y, t}}{\sum_{a} \sum_{l} N_{a, l, y, t}},
$$

where $O_{a, l, y, t}$ corresponds to observed data.

When only length or age distribution is available. It is compared using equation A.8 described above but considering all ages or all lengths, respectively.

\section{Catch statistic}

Mean length at age for commercial fleets are compared using an unweighted sum of squares of mean length likelihood function (lengthnostddev):

$$
\ell=\sum_{y} \sum_{t} \sum_{a}\left(\left(x_{a, y, t}-\mu_{a, y, t}\right)^{2} N_{a, y, t}\right)
$$

where $x_{a, y, t}$ is the sample mean weight from the data for the timestep/age combination, $\mu_{a, y, t}$ is the mean lenght at age calculated from the model for the same combination and $N_{a, y, t}$ is the number of individuals for the same combination.

\section{Understocking}

If the total consumption of fish by all the predators (fleets in this case) amounts to more than the biomass of prey available, then the model runs into "understocking". In this case, the consumption by the predators 
is adjusted so that no more than $95 \%$ of the available prey biomass is consumed, and a penalty, given by the equation A.12 below, is applied to the likelihood score obtained from the simulation (Stefansson, 2005).

$$
\ell=\sum_{t} U_{t}^{2}
$$

where $U_{t}$ is the understocking that has occurred in the model for that timestep.

\section{Penalties}

The BoundLikelihood likelihood component is used to give a penalty weight to parameters that have moved beyond the bounds in the optimisation process. This component does specify the penalty that is to be applied when these bounds are exceeded.

$$
\ell_{i}= \begin{cases}l w_{i}\left(v a l_{i}-l b_{i}\right)^{2} & \text { if } v a l_{i}<l b_{i} \\ u w_{i}\left(v a l_{i}-u b_{i}\right)^{2} & \text { if } v a l_{i}>u b_{i} \\ 0 & \text { otherwise }\end{cases}
$$

Where $l w_{i}=10000$ and $u w_{i}=10000$ are the weights applied when the parameter exceeds the lower and upper bounds, respectively, $v a l_{i}$ is the value of the parameter and, $l b_{i}$ and $u b_{i}$ are the lower and upper bounds defined for the parameter.

\section{Iterative re-weighting}

The total objective function is a weighted sum of all likelihoods components. The weight for each component is determined with an iterative process following the approach presented in Taylor et al. (2007) and in the apppendix of Elvarsson et al. (2014) based on the iterative reweighting scheme of Stefánsson (1998) and Stefansson (2003), which is summarized as follows:

Let $\mathbf{w}_{\mathbf{r}}$ be a vector of length $L$ with the weights of the likelihood components (excluding understocking and penalties) for the run $r$, and $S S_{i, r}, i=1, \ldots, L$, the likelihood score of component $i$ after run $r$. First, a Gadget optimization run is performed to get a likelihood score $\left(S S_{i, 1}\right)$ for each likelihood component assuming that all components have a weight equal to one, i.e., $\mathbf{w}_{\mathbf{1}}=(1,1, \ldots, 1)$. Then, a separated optimization run for each of the components ( $L$ optimization runs) is performed using the following weight vectors:

$$
\mathbf{w}_{\mathbf{i}+\mathbf{1}}=\left(1 / S S_{1,1}, \ldots,\left(1 / S S_{i, 1}\right) * 10000,1 / S S_{i+1,1}, \ldots, 1 / S S_{L, 1}\right), i=1, \ldots, L
$$

Resulting likelihood scores $S S_{i, i+1}$ are then used to calculate the residual variance, $\hat{\sigma}_{i}^{2}=S S_{i, i+1} / d f^{*}$ for each 
component, that is used to define the final weight vector as

$$
\mathbf{w}=\left(1 / \hat{\sigma}_{1}^{2}, \ldots, 1 / \hat{\sigma}_{L}^{2}\right)
$$

Degrees of freedom $d f^{*}$ is approximated by the number of non-zero data points in the observed data for each component.

\section{A.3. Fit to data}

How well the model fits to age and length data were used as a validation procedure. Model outputs for length and age distributions are presented in Figures A.2 and A.3

Please note that a complete model validation would require to setting up a larger experiment for simulations of input data or bootstraping.

\section{A.4. Forecasting}

It was necessary to modify the internal structure of gadget.forward function to include different recruitment assumptions. The modified function can be found at https://github.com/mmrinconh/gadgetanchovy/blob/ master/Anchovy79/gadget_forward_mod_scenarios.r.

\section{B. Reproducibility}

Here we summarize the procedure to follow in order to reproduce this document. We assume that the reader have already installed $\mathrm{R}$ and Rstudio.

1. Install the package knitr in $\mathrm{R}$ following the instructions given in https://cran.r-project.org/web/ packages/knitr/index.html

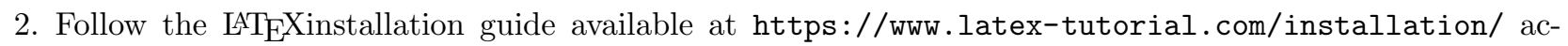
cording to your operating system.

3. Unzip the 'Reproducible.zip' file available as Supplementary Material and open the Rnw file ('Rincon_et_al_MS_rep.Rnw') with Rstudio.

4. Click on the 'Compile PDF' button which is locatted on the top left of the screen. This step will produce a set of files, among them a pdf file (.pdf) which is an exact copy of this document. 


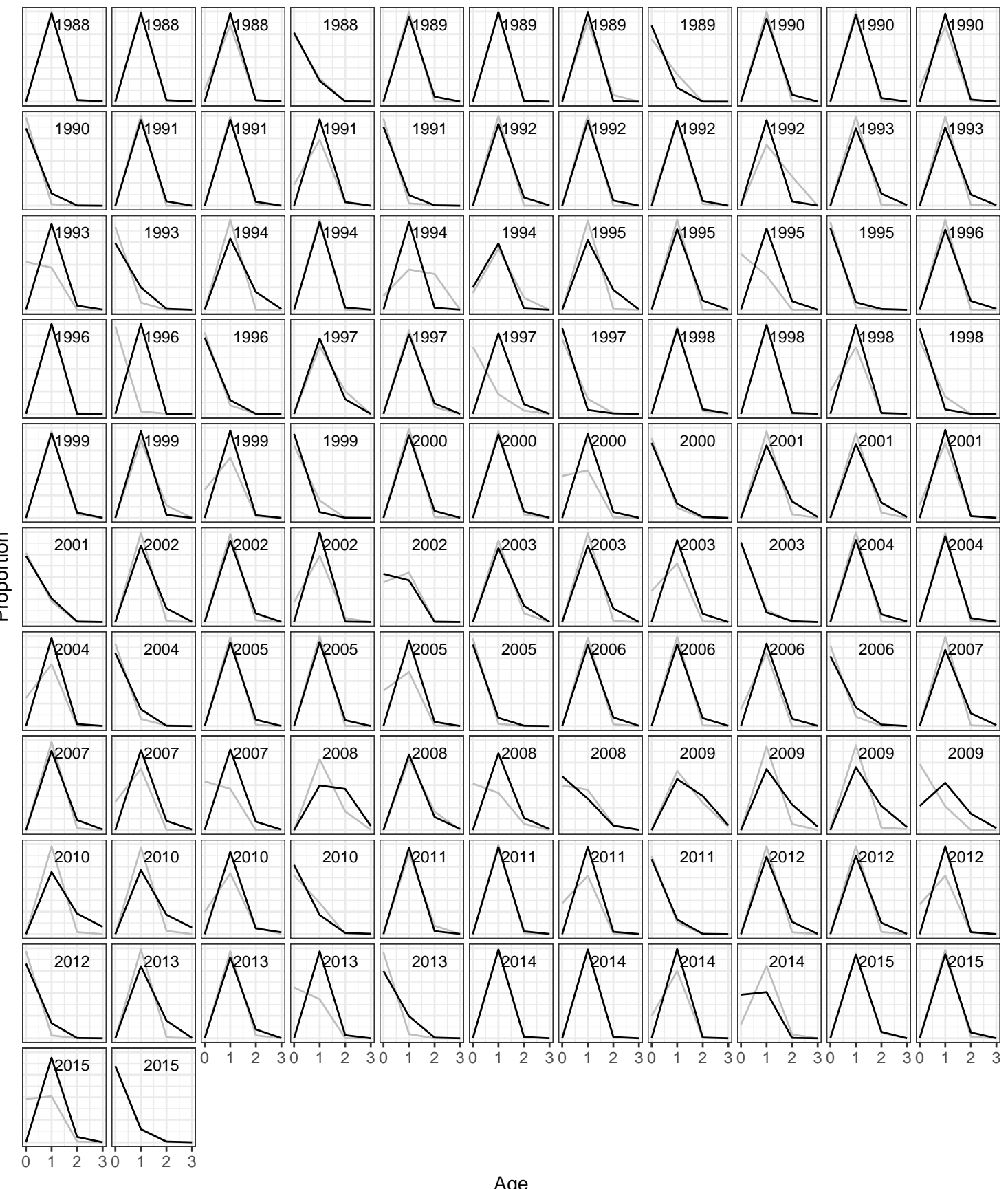

Age

Figure A.2: Comparison between observed and estimated catches age distribution. Grey lines represent observed data while black lines represent estimated data. 


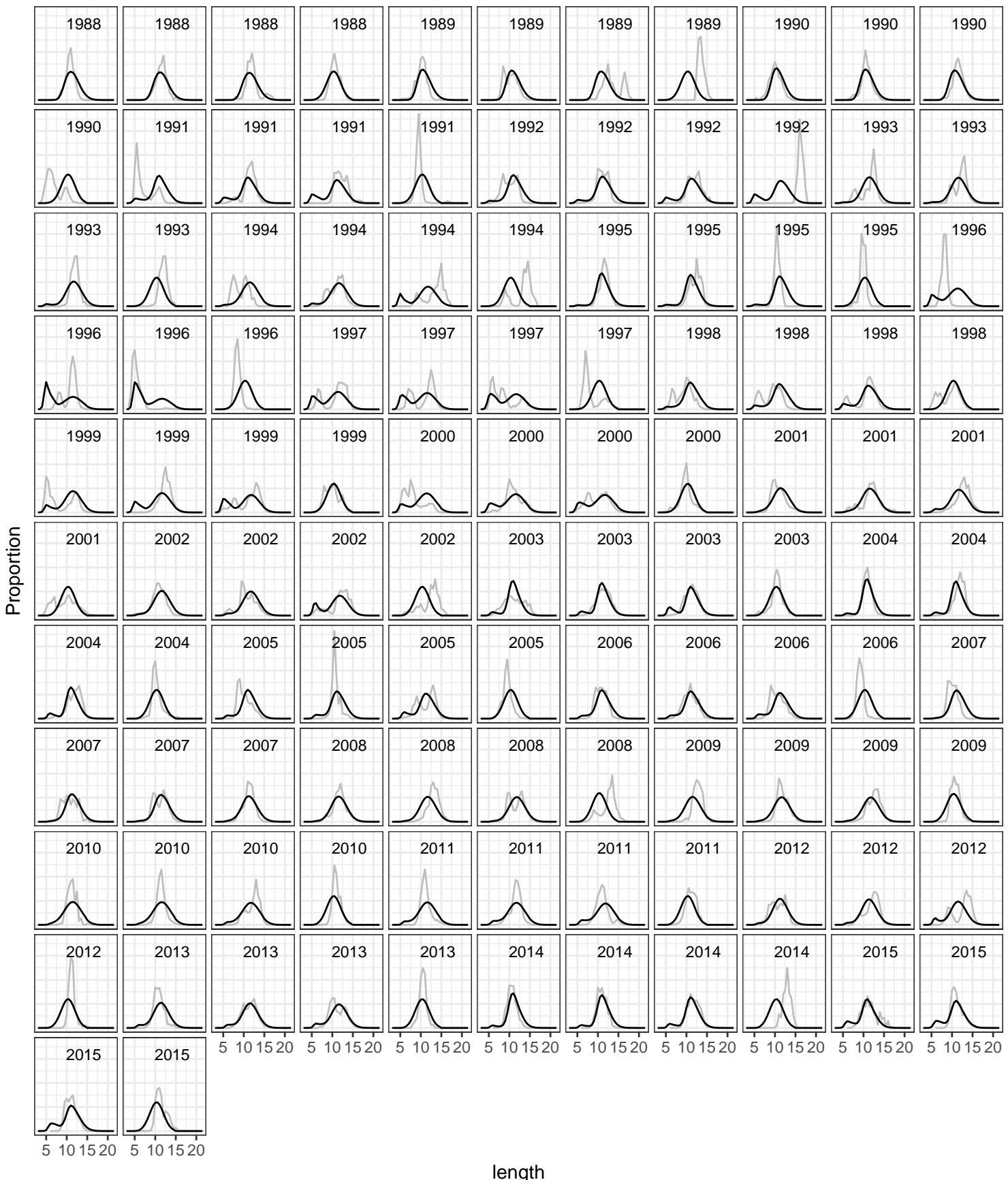

Figure A.3: Comparison between observed and estimated catches length distribution. Grey lines represent observed data while black lines represent estimated data 